\title{
The expression of miR-21 and miR-143 is deregulated by the HPV16 E7 oncoprotein and 17 $\beta$-estradiol
}

\author{
YAZMÍN GÓMEZ-GÓMEZ ${ }^{1,2^{*}}$, JORGE ORGANISTA-NAVA ${ }^{1,2^{*}}$, RODOLFO OCADIZ-DELGADO $^{2}$, \\ ENRIQUE GARCÍA-VILLA ${ }^{2}$, MARCO ANTONIO LEYVA-VAZQUEZ ${ }^{3}$, BERENICE ILLADES-AGUIAR ${ }^{3}$, \\ PAUL F. LAMBERT ${ }^{4}$, ALEJANDRO GARCÍA-CARRANCÁ ${ }^{5}$ and PATRICIO GARIGLIO ${ }^{2}$
}

${ }^{1}$ Programa de Doctorado en Ciencias Biomédicas, Instituto de Fisiología Celular (IFC), Universidad Nacional Autónoma de México (UNAM), Ciudad de México 04510; ${ }^{2}$ Department of Genetics and Molecular Biology, Center for Research and Advanced Studies of the National Polytechnic Institute (CINVESTAV-IPN), Mexico city 07360; ${ }^{3}$ Laboratory of Molecular

Biomedicine, Academic Unit of Chemical-Biological Sciences, Guerrero State University, Chilpancingo 39090, Guerrero, Mexico; ${ }^{4}$ McArdle Laboratory for Cancer Research, University of Wisconsin School of Medicine and Public Health, Madison, WI 53706, USA; ${ }^{5}$ Cancer Biomedical Research Unit, National Cancer Institute and Biomedical Research Institute, Biomedical Research Institute, National Autonomous University of Mexico and Division of Basic Research, National Cancer Institute (INCan), Mexico city 14080, Mexico

Received March 1, 2016; Accepted April 15, 2016

DOI: $10.3892 /$ ijo.2016.3575

\begin{abstract}
MicroRNAs (miRNAs) are a class of non-coding RNAs that negatively regulate their target mRNAs at a posttranscriptional level, thereby affecting crucial processes in cancer development. However, little is known about the molecular events that control expression of miRNAs in cervical cancer (CC). HPV16 E7 oncoprotein in conjunction with estrogen are sufficient to produce high grade cervical dysplasia and invasive cervical malignancies in a mouse model. In the present study, we determined the potential role that the E7 oncoprotein and $17 \beta$-estradiol $\left(\mathrm{E}_{2}\right)$ play in the deregulation of miR-21 and miR-143 expression levels by these two risk factors. We found that, while the expression of miR-21 was upregulated and the expression of miR-143 was downregulated by the HPV16 E7 oncoprotein in vivo, and in vitro and that $\mathrm{E}_{2}$ treatment is also implicated in the deregulation of these important miRNAs in vivo. Sustained upregulation of miR-21 resulted in suppression of PTEN expression, and repression of
\end{abstract}

Correspondence to: Professor Patricio Gariglio, Department of Genetics and Molecular Biology, Center for Research and Advanced Studies of the National Polytechnic Institute (CINVESTAV-IPN), Av. IPN 2508. Colonia San Pedro Zacatenco, Ciudad de México 07360, México

E-mail:vidal@cinvestav.mx

Dr Alejandro García-Carrancá, Laboratory of Virus and Cancer, National Cancer Institute, Av. San Fernando No. 22, Sección XVI, Tlalpan, Ciudad de México 14080, México

E-mail: carranca@biomedicas.unam.mx

*Contributed equally

Key words: cervical cancer, miR-21, miR-143, E7 oncoprotein, estrogens
miR-143 increased the mRNA and protein levels from Bcl-2. These results suggested that HPV type 16 E7 oncoprotein and $\mathrm{E}_{2}$ play an important role in regulating miR-21 and miR-143 expression. We have observed similar results in CC patients containing HPV16 sequences, suggesting that these miRNAs could serve as diagnostic biomarkers in CC. The present study highlights the roles of miRNAs in cervical tissue and implicates these important molecules in cervical carcinogenesis.

\section{Introduction}

Cervical cancer (CC), the third most common cancer among women worldwide (1), is strongly associated with infection and subsequent transformation of cervical cells by high risk-human papillomavirus (HR-HPVs) (2), of which HPV16 the most prevalent high-risk genotype in CC (3). The HR-HPVs contain three major viral oncoproteins: E5, E6 and E7, which are involved in the induction and maintenance of the transformed phenotype (4). The E7 oncoprotein is the major transforming protein and in the context of genetically engineered mice expressing E7 in cooperation with estradiol $\left(\mathrm{E}_{2}\right)$ it induces cervical tumors (5), in part due to the E7 functions shown previously to dysregulate the cell cycle including: E7 binding, destabilization and consequent destruction of pRb (6). HPV16/18 E7 has been shown to associate and modify the normal activities of cellular regulatory complexes altering cellular gene expression $(6,7)$. Moreover, $\mathrm{E}_{2}$ binds to the estrogen receptor (ER) to regulate the transcription of many genes through both genomic and non-genomic pathways $(8,9)$. Genomic pathways include the classical interactions of ligand-bound ER dimers with estrogen-responsive elements in target gene promoters, in which ER interacts with Sp1, AP1 and NF- $\kappa \mathrm{B}$ proteins. Non-genomic pathways involve effects through cell surface receptors linked to the mitogen-activated protein kinase pathway $(8,9)$ and may indirectly regulate gene activity (8). 
MicroRNAs (miRNAs or miRs) are an abundant class of small non-coding RNA molecules that measure approximately 22 nucleotides in length. They function to regulate gene expression at the post-transcriptional level by mRNA degradation or alternatively by translational repression of protein-coding mRNAs (10). Moreover, miRNAs function as oncogenes or tumor suppressor, depending on the cellular context and the target genes (11). By targeting mRNAs, miRNAs play critical roles in cell proliferation (12) and apoptosis (13), as well as in the initiation and progression of cancer $(14,15)$. Several studies have documented a relationship between the aberrant expression of a class of miRNAs and the pathogenesis of many human cancers $(11,14,16)$, including CC (17-22). Even though miR-21 and miR-143 are aberrantly expressed in CC and are closely related to $\mathrm{CC}$ development $(23,24)$, the participation of the E7 oncoprotein and the hormonal environment have not been studied. miR-21 functions as an oncogene by targeting tumor suppressor genes including tropomyosin 1 (TPM1), programmed cell death 4 (PDCD4), and phosphatase and tensin homolog (PTEN); increase in miR-21 levels leads to cell proliferation and inhibition of apoptosis, inducing cancer invasion and metastasis (25). The promoter regulatory region of miR-21 gene consists of several binding sites for transcription factors such as activator protein 1 (AP1), and signal transducer and activator of transcription 3 (STAT3) (26). In contrast, miR-143 through the regulation of antiapoptotic $\mathrm{Bcl}-2$ may play an important role in the pathogenesis of $\mathrm{CC}$ as tumor suppressor; overexpression of miR-143 in HeLa cells results in apoptosis and suppression of both $\mathrm{Bcl}-2$ expression and cell proliferation (27). Furthermore, the presence of the $\mathrm{Bcl}-2$ protein is strongly associated with the development of CC (28) and was significantly correlated to the grades of cervical intraepithelial neoplasia (29).

The HR-HPVs are responsible for the upregulation of oncogenic and/or downregulation of tumor suppressive miRNAs through their viral oncoproteins. The HR-HPV16 E7 oncoprotein upregulates the expression of miR-15b and miR-27b $(30,31) . E_{2}$ has also been involved in regulating the expression of microRNAs with tumor suppressor and oncogenic functions. $\mathrm{E}_{2}$ induces 21 miRNAs and represses seven miRNAs in MCF-7 breast cancer cells that have the potential to control $420 \mathrm{E}_{2}$-regulated mRNAs at the post-transcriptional level (32).

In the present study we investigated if HPV16 E7 oncoprotein and $17 \beta$-estradiol deregulate the expression of miR-21 and miR-143 and their target genes, PTEN and Bcl-2, respectively. We found that in the presence of HPV16 E7 oncoprotein and $\mathrm{E}_{2}$, miR-21 expression was upregulated, while miR-143 expression was downregulated. In addition, we observed a negative correlation between miR-21 and miR-143 expression and their target genes in vitro and in vivo.

\section{Materials and methods}

Clinical samples. We analyzed cervical scrapings from 10 HPV negative healthy women and 14 HPV16 positive cervical samples (biopsy tissues) from patients with CC, samples were obtained in the Molecular Biomedicine and Cytopathology Laboratories at the School of Chemistry and Biology of the Autonomous University of Guerrero in Chilpancingo Guerrero, and National Cancer Institute in Mexico City, Mexico between 2012 and 2013. This study was approved by the Bioethical Committee of both institutions. Written informed consent was obtained from all the participants.

The scraped cells from HPV-negative healthy women were suspended in $5 \mathrm{ml}$ ice cold phosphate-buffered saline [(6.4 mM $\mathrm{Na}_{2} \mathrm{HPO}_{4}, 1.5 \mathrm{mM} \mathrm{KH} \mathrm{PO}_{4}, 140 \mathrm{mM} \mathrm{NaCl}$, and $2.7 \mathrm{mM} \mathrm{KCl}$ (pH 7.2)] and kept on ice until further processing. The cell suspension was centrifuged and washed with wash buffer [10 mM Hepes/KOH (pH 7.5), $1.5 \mathrm{mM} \mathrm{MgCl} 2,10 \mathrm{mM} \mathrm{KCl}$ and $1 \mathrm{mM}$ dithiothreitol]; after the pellet was snap-frozen in liquid nitrogen and then stored at $-80^{\circ} \mathrm{C}$ until used for miRNAs and mRNA quantification.

Cell lines. Osteosarcoma Saos2 cell line was obtained from the American Type Culture Collection (ATCC; Manassas, VA, USA). This cell line was maintained in Dulbecco's modified Eagle's medium (Sigma-Aldrich, St. Louis, MO, USA) with $10 \%$ fetal bovine serum (FBS; Invitrogen, Carlsbad, CA, USA), $2 \mathrm{mM}$ L-glutamine and $100 \mathrm{U} / \mathrm{ml}$ penicillin/streptomycin (Invitrogen) and incubated at $37^{\circ} \mathrm{C}$ in a humidified $5 \%$ $\mathrm{CO}_{2}$ atmosphere. Transfection of the $\mathrm{E} 7$ oncogene (plasmid pcDNA3E7) was performed using Lipofectamine 2000 reagent (Invitrogen) according to the manufacturer's instructions. In order to obtain a stable cell line, transfected cells were selected for 2 weeks in a growth media containing 1,200 mg/ml of G418 (Invitrogen). To keep clone selection, cells were grown continuously in a medium containing $800 \mathrm{mg} / \mathrm{ml}$ of G418.

Transgenic mice. The K14E7HPV16 transgenic (K14E7) and $\mathrm{FvB} / \mathrm{n}$ control [non-transgenic (NT)] mice have been previously described $(5,33)$. K14E7 mice were backcrossed in the $\mathrm{FVB} / \mathrm{n}$ background, maintained and used as heterozygotes in our experiments. The mice were housed in a pathogen-free barrier facility, according to the Association for Assessment and Accreditation of Laboratory Animal Care International (AAALAC-International). All the experiments and procedures were approved by the Research Unit for Laboratory Animal Care Committee (UPEAL-Cinvestav-IPN, Mexico; NOM-062-ZOO-1999).

Hormone treatment. Mice were treated with $17 \beta$-estradiol $\left(E_{2}\right)$ as previously reported (5). Briefly, one month-old virgin female E7 transgenic and NT mice were s.c. implanted in the dorsal skin with continuous release pellets delivering $0.05 \mathrm{mg}$ $\mathrm{E}_{2}$ over 60 days (Innovative Research of America, Sarasota, FL, USA). Mice were treated with hormone for 6 months; the treatment time required the insertion of three pellets. Groups of 5 transgenic and NT female mice were used for this study.

Harvesting of the of specimens. After sacrifice by cervical dislocation, cervical tissue was rapidly removed and was immediately stored in RNAlater solution (Ambion, USA) at $4^{\circ} \mathrm{C}$ overnight. Tissue was recovered from the solution with sterile forceps, quickly blotted to remove excess RNAlater and immediately snap frozen in liquid nitrogen.

Total RNA extraction. Total RNA (large and small size RNAs) was extracted from cultured cells and cervical tissue. For total RNA extraction the TRIzol method (Invitrogen) was employed 
Table I. Primer sequences used in the present study.

\begin{tabular}{|c|c|c|c|c|}
\hline $\begin{array}{l}\text { Gene } \\
\text { symbol }\end{array}$ & Forward primer & Reverse primer & Temp. $\left({ }^{\circ} \mathrm{C}\right)$ & $\begin{array}{c}\text { Amplicon } \\
\text { size (bp) }\end{array}$ \\
\hline \multicolumn{5}{|l|}{ Mouse } \\
\hline PTEN & GGATGTCGTCCTGAAGGGAG & GCTTCGCTGGAGGAACCTG & 60 & 108 \\
\hline BCL2 & ACTTCGCAGAGATGTCCAGTCA & TGGCAAAGCGTCCCCTC & 60 & 63 \\
\hline HPRT & CCAGCAAGCTTGCAACCTTAAC & GTAATGATCAGTCAACGGGGG & 60 & 177 \\
\hline \multicolumn{5}{|l|}{ Human } \\
\hline PTEN & GGTCATGTGTGTGGAGAGC & GATCCAGGTGTGCAGGTG & 60 & 78 \\
\hline BCL2 & CCGAAAGGTTTTGCTACCATTCT & AAAATTATTTCCTTTCTGAGCATTCC & 60 & 105 \\
\hline$\beta 2 \mathrm{M}$ & ACCCCCACTGAAAAAGATGAG & ATGATGCTGCTTACATGTCTCG & 60 & 100 \\
\hline
\end{tabular}

according to the manufacturer's protocol, and the quality and concentration of RNA were spectrophotometrically assessed by measuring absorbance at A260/280 and by agarose gels stained with ethidium bromide.

Quantification of miRNAs and mRNA levels using real-time $P C R$. To detect the levels of mature miRNA in cultured cells and cervical tissue, 1-10 ng of total RNA were reverse transcribed to cDNA with specific RT primers using TaqMan ${ }^{\circledR}$ MicroRNA reverse transcription kit (Applied Biosystems, Foster City, CA, USA). Stem-loop real-time PCR [miR-21 (ID 000397) and miR-143 (002249)] was used to detect miRNAs level by the TaqMan ${ }^{\circledR}$ MicroRNA assays (Applied Biosystems). The PCR cycles were as follows: $94^{\circ} \mathrm{C}$ for $5 \mathrm{~min}$, followed by 40 cycles of $94^{\circ} \mathrm{C}$ for $30 \mathrm{sec}, 60^{\circ} \mathrm{C}$ for $30 \mathrm{sec}$. Real-time reverse transcription-polymerase chain reactions were performed in an Applied Biosystems 7300 Detection system (Applied Biosystems). Relative expression levels were normalized to the expression of endogenous control snoRNA202 (001232; Applied Biosystems).

For specific mRNA quantification, total RNA (1 $\mu \mathrm{g})$ was reverse transcribed into cDNA by priming with oligo (dT) and cDNA synthesis by the SuperScript II First-Strand Synthesis System (Invitrogen) for RT-PCR according to the manufacturer's instructions. Real-time PCR was performed using an Applied Biosystems 7300 Detection system (Applied Biosystems), using SYBR-Green (SYBR-Green PCR reagents kit; Applied Biosystems) and the protocol provided by the manufacturer. Annealing temperatures and $\mathrm{MgCl}_{2}$ concentrations were optimized to create a one-peak melting curve. Additionally, the amplicons were checked by agarose gel electrophoresis for a single band of the expected size. PCRs were processed through 40 cycles of a 3-step PCR, including $60 \mathrm{sec}$ of denaturation at $95^{\circ} \mathrm{C}, 60 \mathrm{sec}$ primer dependent annealing phase (Table I), and $60 \mathrm{sec}$ template-dependent elongation at $72^{\circ} \mathrm{C}$.

The reaction $(25 \mu \mathrm{l})$ consisted of $12.5 \mu \mathrm{l}$ SYBR-Green PCR Master Mix (Applied Biosystems) containing: Taq DNA polymerase, reaction buffer, dNTP mix, $1 \mathrm{mM} \mathrm{MgCl}_{2}$ (final concentration) and SYBR-Green I dye, $1 \mu \mathrm{l}$ of each primer
$(0.5 \mu \mathrm{M}), 500 \mathrm{ng}$ template per reaction and ultrapure water. All primer sequences and product sizes are described in Table I. All reactions were performed on five independent mice, and relative expression levels were normalized to the expression of HPRT mRNA. The expression of miRNA and mRNA was determined from the threshold cycle $\left(\mathrm{C}_{t}\right)$, and the relative expression levels were calculated by the $2^{-\Delta \Delta \mathrm{Ct}}$ method (34).

Western blot analysis. Frozen $\left(-70^{\circ} \mathrm{C}\right)$ cervical samples were pulverized with a mortar and pestle in liquid nitrogen. Cells and cervical samples were lysed on ice in lysis buffer $(25 \mathrm{mM}$ Tris, $\mathrm{pH} 7.5,150 \mathrm{mM} \mathrm{NaCl}, 1 \% \mathrm{NP}-40,0.5 \%$ sodium deoxycholate and $0.1 \%$ SDS) containing proteinase inhibitors and incubated on ice for $30 \mathrm{~min}$. Following centrifugation at $16,000 \mathrm{x} \mathrm{g}$ for $15 \mathrm{~min}$ at $4^{\circ} \mathrm{C}$, the supernatant containing the total cell extract was collected and aliquots were kept at $-80^{\circ} \mathrm{C}$. The protein concentrations were measured by the Bradford assay; proteins were heat denatured and ran on $10 \%$ SDS-PAGE gels. The proteins were transferred onto nitrocellulose membranes and, after blocking with $10 \%$ non-fat milk in PBS containg $0.1 \%$ Tween-20 (PBST) for $1 \mathrm{~h}$, the membranes were incubated overnight with diluted (1:500) primary antibody. The following primary antibodies were used: PTEN (Sc-7974; Santa Cruz Biotechnology, Santa Cruz, CA, USA) and Bcl-2 (Sc-7382, Santa Cruz Biotechnology). The next day, blots were washed three times for 5 min each with PBST and incubated with HRP-conjugated anti-mouse or anti-rabbit secondary antibody (Sigma) for $1 \mathrm{~h}$ at room temperature. The stained membranes were visualized by enhanced chemiluminescence reaction using the SuperSignal West Pico Chemiluminescent Substrate (Thermo Fisher Scientific).

Statistical analysis. Data were analyzed using GraphPad Prism software (v5.0; GraphPad Software, Inc., La Jolla, CA, USA). Mann-Whitney test was used to compare differences among miRNA, mRNA and protein expression levels between groups and results were presented as mean \pm standard deviation (SD). $\mathrm{P}$-values $<0.05$ were considered significantly different between data sets. 

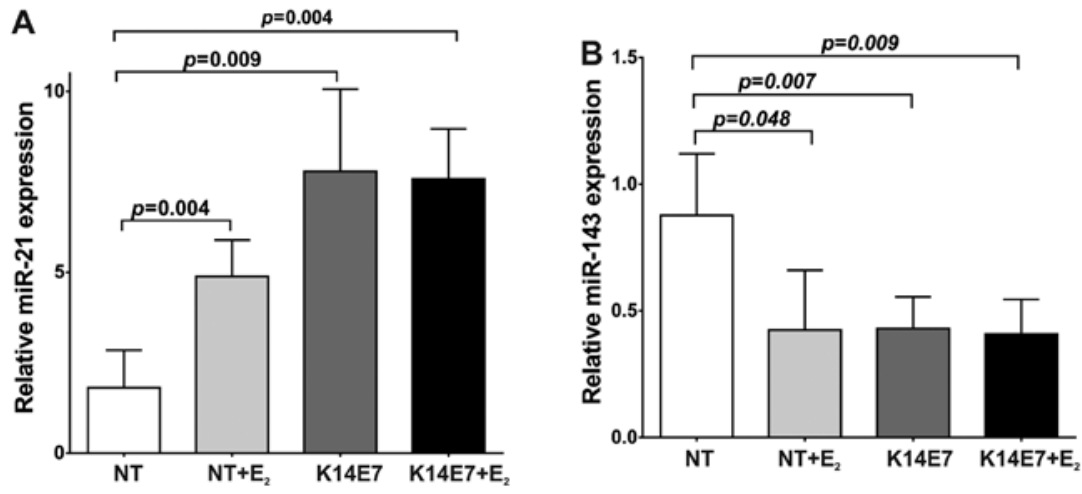

Figure 1. Effect of the $\mathrm{E} 7$ oncoprotein, $\mathrm{E}_{2}$ and $\mathrm{E} 7+\mathrm{E}_{2}$ on miR-21 and miR-143 expression levels in the cervix of 7 month-old mice. (A) miR-21 and (B) miR-143 expression levels in cervical tissue from K14E7 and NT mice with and without $\mathrm{E}_{2}$ treatment during 6 months (7 months of age). TaqMan microRNA assay was carried out to detect the mature form of microRNAs, as described in Materials and methods. Experiments were performed in each of five mice per group; values normalized to Sno202 were expressed as means \pm SD. Mann-Whitney test was performed and statistical significance was determined as $\mathrm{P}<0.05$. Bars represent mean. Error bars represent SD. $\mathrm{E}_{2}, 17 \beta$-estradiol; NT, non-transgenic.

\section{Results}

The E7 oncoprotein and $17 \beta$-estradiol affect miR-21 and miR-143 expression in cervical tissue of K14E7 transgenic mice. It is well known that high-risk HPV16 infection and estradiol are considered as risks factors for CC. The HPV E7 oncoprotein is the primary factor responsible for blocking cell cycle exit during differentiation $(3,35)$. Given that in the transgenic model of cervical cancer (K14E7 mice) chronic exposure to $17 \beta$-estradiol $\left(\mathrm{E}_{2}\right)$ is important for neoplasia development, we investigated in mice cervical tissue the individual and combined effect of $E_{2}$ and the HPV16 E7 oncoprotein on the expression of miR-21 and miR-143, known to play a role in the modulation of cell proliferation and survival genes. Reverse transcription quantitative polymerase chain reaction (RT-qPCR) analysis of miRNA from cervical tissue clearly showed that the expression level of miR-21 was significantly higher in $\mathrm{E} 7$ or $\mathrm{E}_{2}$ treated mice. Compared to non-transgenic mice (NT), miR-21 expression levels in $\mathrm{NT}+\mathrm{E}_{2}$ mice were increased with an average fold change of 4.88 -fold $(\mathrm{P}=0.004$; Fig. 1A). In K14E7 transgenic mice without $\mathrm{E}_{2}$ treatment miR-21 was also strongly increased (7.77-fold) compared to NT mice ( $\mathrm{P}=0.009$; Fig. 1A). In $\mathrm{K} 14 \mathrm{E} 7+\mathrm{E}_{2}$ mice the average fold change of oncogenic miR-21 was 7.58-fold ( $\mathrm{P}=0.004$; Fig. 1A). Thus, in 7 month-old mice, both HPV16E7 oncoprotein and $E_{2}$ clearly induce miR-21 overexpression. In contrast to miR-21, the levels of miR-143, considered tumor suppressor miRNA, are significantly low in cervical tissue containing E7 or $E_{2}$. When compared to NT mice, the miR-143 expression in $\mathrm{NT}+\mathrm{E}_{2}$ mice was significantly decreased (the average fold change was 0.42 -fold) (Fig. 1B). In cervix of K14E7 mice without $\mathrm{E}_{2}$ treatment the miR-143 expression level was also significantly decreased (0.43-fold) ( $\mathrm{P}=0.007$; Fig. 1B). Likewise, in $\mathrm{K} 14 \mathrm{E} 7+\mathrm{E}_{2}$ transgenic mice the average fold change of miR-143 was lower (0.41-fold) compared to NT mice $(\mathrm{P}=0.009$; Fig. 1B). These data show that in 7 month-old mice the presence of $\mathrm{E}_{2}$ or of the $\mathrm{E} 7$ oncoprotein, increased the levels of miR-21 while decreased those of miR-143.

Expression of miRNA target genes in K14E7 cervical tissue. It has been reported that miR-21 is involved in the regula- tion of PTEN, while miR-143 regulates the Bcl-2 expression in CC. Employing the K14E7 model, we explored whether the $\mathrm{E}_{2}$ and E7-induced miR-21 upregulation can repress the levels of mRNA and protein for an important target gene, the phosphatase-tensin homolog (PTEN). Surprisingly, we observed that both PTEN mRNA and protein expression were upregulated in $\mathrm{NT}+\mathrm{E}_{2}$ mice as compared with $\mathrm{NT}$ (mRNA, 1.69-fold; protein, 1.93-fold; Fig. 2A and C). The cervical tissue from K14E7 transgenic mice expressed a significantly lower level of PTEN mRNA (0.07-fold), while that in K14E7+ $\mathrm{E}_{2}$ mice expressed 0.23-fold compared to NT mice (Fig. 2A). Similarly, PTEN protein levels also decreased in K14E7 and $\mathrm{K} 14 \mathrm{E} 7+\mathrm{E}_{2}$ mice compared to NT mice, although the decrease in $\mathrm{K} 14 \mathrm{E} 7+\mathrm{E}_{2}$ mice was not statistically significant $(\mathrm{P}=0.258)$. However, when compared with $\mathrm{NT}+\mathrm{E}_{2}, \mathrm{~K} 14 \mathrm{E} 7+\mathrm{E}_{2}$ showed a significant decrease $(\mathrm{P}=0.036)$ in cervical tissue. We observed a significant inverse correlation between miR-21 and PTEN mRNA and protein expression in the K14E7 transgenic mice (Pearson's correlation $\mathrm{r}=-0.881, \mathrm{P}=0.049 ; \mathrm{r}=-0.898, \mathrm{P}=0.039$, respectively), but not in $\mathrm{NT}+\mathrm{E}_{2}$ and $\mathrm{K} 14 \mathrm{E} 7+\mathrm{E}_{2}$ (Table II).

The expression of miR-143 was significantly decreased by $\mathrm{E}_{2}$ and E7 in cervical tissue (Fig. 1B). To explore whether this downregulated miR-143 may increase the mRNA and protein levels of an important target gene, the expression of B-cell lymphoma (BCL-2) was determined. We performed RT-qPCR and western blot analysis to determine whether this low miR-143 level leads to increased BCL-2 mRNA and protein levels in cervical cancer. As shown in Fig. 2B downregulated miR-143 induced a significant increase in BCL-2 mRNA $\left(\mathrm{NT}+\mathrm{E}_{2}, 4.94 ; \mathrm{K} 14 \mathrm{E} 7,3.75 ; \mathrm{K} 14 \mathrm{E} 7+\mathrm{E}_{2}, 6.11\right)$ as compared with NT mice. Similarly, BCL-2 protein levels were increased when miR-143 was downregulated $\left(\mathrm{NT}+\mathrm{E}_{2}, 2.07\right.$; K14E7, 2.60; K14E7+ $\mathrm{E}_{2}, 3.56$ ) (Fig. 2D). A strong inverse correlation between miR-143 expression levels and BCL-2 mRNA and protein levels was observed in cervical tissues from transgenic K14E7 mice, evaluated by Pearson's correlation ( $\mathrm{r}=-0.939$, $\mathrm{P}=0.018 ; \mathrm{r}=-0.956, \mathrm{P}=0.044$, respectively) (Table II). Our results indicate that PTEN expression was downregulated and BCL-2 expression was upregulated in K14E7 cervical cancer correlating with miR-21 being upregulated and miR-143 downregulated, respectively. 
A

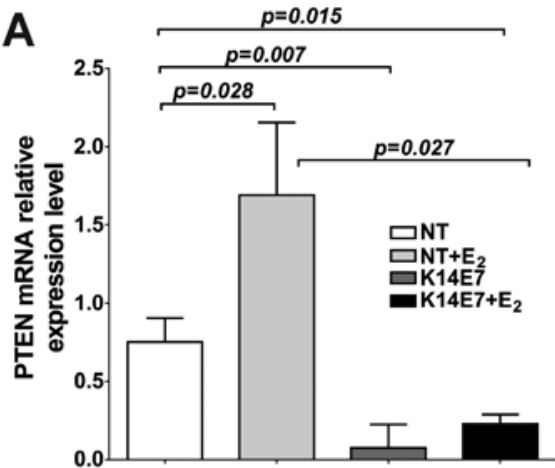

C

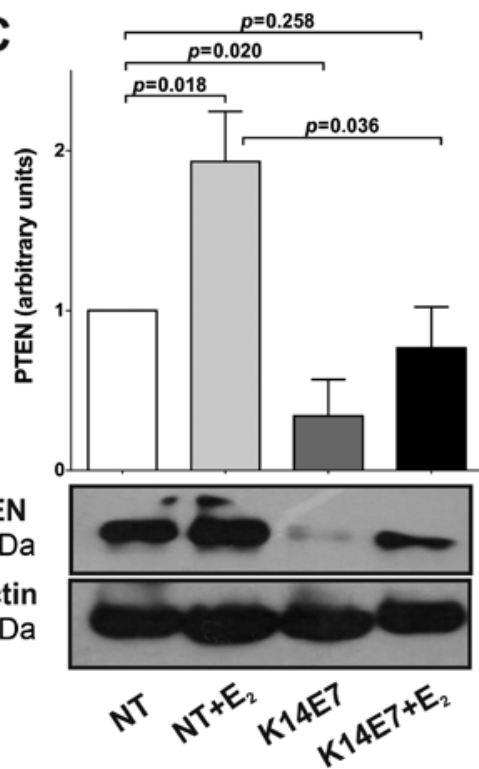

B

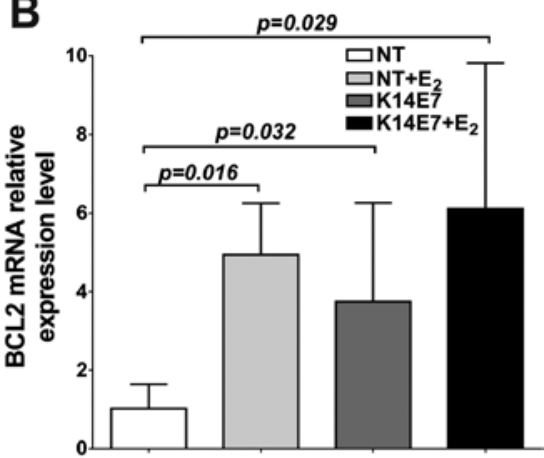

D
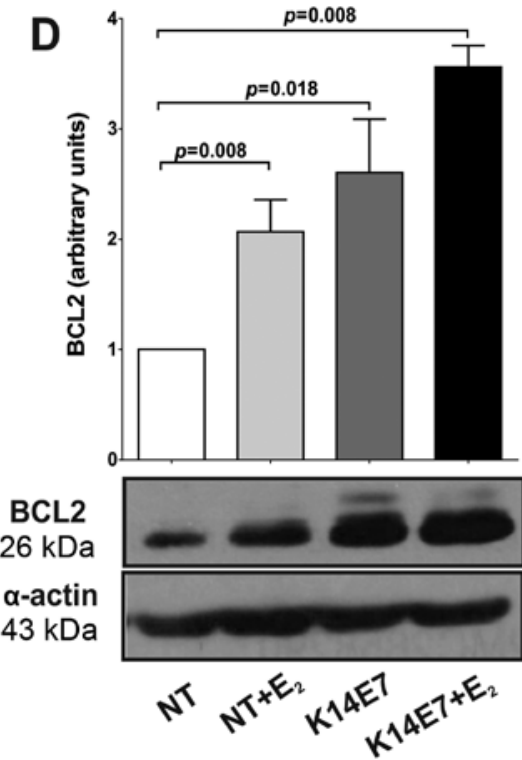

Figure 2. Expression levels of PTEN and BCL2 in the cervical cancer model. (A and B) Reverse transcription quantitative polymerase chain reaction (RT-qPCR) was performed to determine the mRNA expression levels of PTEN and BCL2. (C and D) Western blot analysis (WB) and quantitative densitometry of PTEN and BCL2 proteins. RT-qPCR experiments were performed in quintuplicate and values are expressed as means \pm SD (normalized to HPRT); Mann-Whitney test was performed and statistical significance was determined as $\mathrm{P}<0.05$ comparing expression in squamous epithelium from the cervix of NT mice vs. NT+E $\mathrm{E}_{2}, \mathrm{~K} 14 \mathrm{E} 7$ and $\mathrm{K} 14 \mathrm{E} 7+\mathrm{E}_{2}$ mice. The WB analysis was performed in cervical tissue from NT mice and K14E7 transgenic mice with and without $\mathrm{E}_{2}$ treatment. Experiments were performed in quintuplicate and normalized to $\alpha$-actin. A representative WB experiment is shown in panels $\mathrm{C}$ and D. Bars represent mean. Error bars represent SD. Statistical significance was determined as $\mathrm{P}<0.05$. $\mathrm{E}_{2}, 17 \beta$-estradiol; NT, non-transgenic.

Table II. Pearson's correlation coefficients between miRNA expression, mRNA levels and protein levels.

\begin{tabular}{|c|c|c|c|c|c|}
\hline \multicolumn{2}{|c|}{$\mathrm{NT}+\mathrm{E}_{2}$} & \multicolumn{2}{|c|}{ K14E7 } & \multicolumn{2}{|c|}{$\mathrm{K} 14 \mathrm{E} 7+\mathrm{E}_{2}$} \\
\hline $\mathrm{r}$ & P-value & $r$ & P-value & $\mathrm{r}$ & P-value \\
\hline
\end{tabular}

miR-21

miR-21 expression and PTEN mRNA expression

$\begin{array}{llllll}0.952 & 0.048 & -0.881 & 0.049 & -0.928 & 0.071 \\ 0.689 & 0.199 & -0.898 & 0.039 & 0.371 & 0.539\end{array}$

miR-21 expression and PTEN protein levels

0.689

0.199

$-0.898$

0.039

0.539

$\operatorname{miR} 143$

miR-143 expression and BCL2 mRNA expression

$-0.916$

0.029

$-0.939$

0.018

$-0.960$

0.040

miR-143 expression and BCL2 protein levels

$-0.952$

0.048

$-0.956$

0.044

$-0.946$

0.015

The E7 oncoprotein represses PTEN expression by upregulating miR-21 in Saos-2 cells. To confirm that E7 expression can disturb miRNA levels, we stably transfected Saos-2 cells with the HPV16 E7 gene. As shown in Fig. 3A, expression of the $\mathrm{E} 7$ oncoprotein resulted in a 2.14-fold upregulation $(\mathrm{P}=0.029)$ in the expression of miR-21 (Fig. 3A). To explore whether the upregulated expression of miR-21 caused by HPV16 E7 oncoprotein expression, can repress its target genes, the expression of PTEN was measured by RT-qPCR and western blot analysis. As shown in Fig. 4A and B, the expression of PTEN 
A

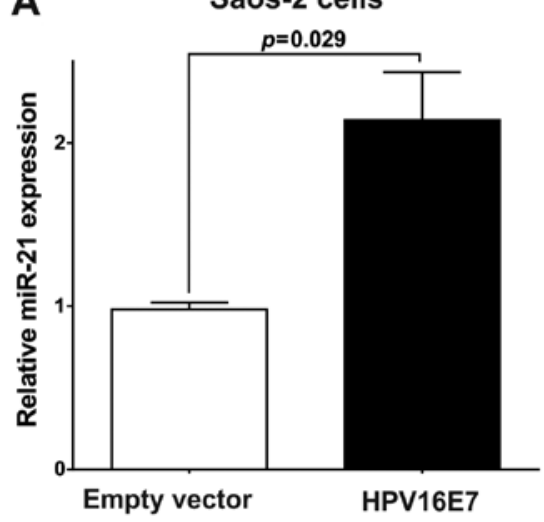

B

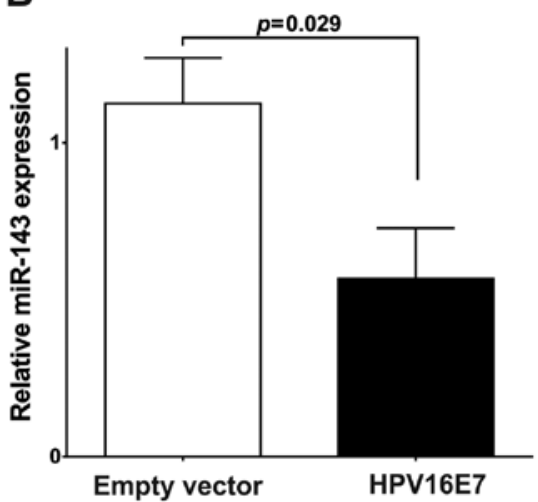

C

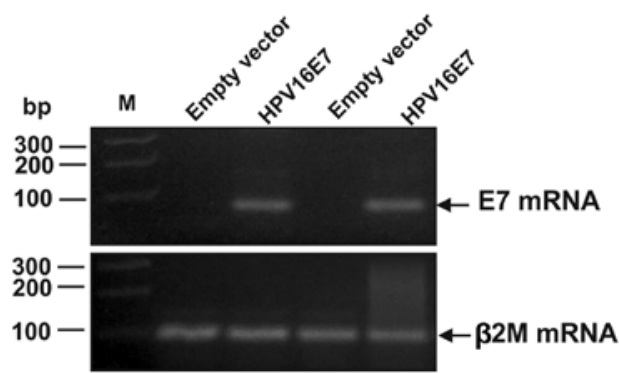

Figure 3. Effect of HPV16 E7 oncoprotein on miR-21 and miR-143 expression levels. Saos-2 cells were stably transfected with either pcDNA3 (empty vector) or with plasmid expressing HPV16 E7 protein (pcDNA3E7), as indicated in Materials and methods. Data obtained by RT-qPCR amplification miR-21 and miR-143 are plotted. (A) The expression level of miR-21 in stably E7 transfected Saos-2 cells was significantly upregulated (median \pm SD; $2.14 \pm 0.58, P=0.029$ ). (B) The expression level of miR-143 was significantly downregulated (median $\pm \mathrm{SD} ; 0.56 \pm 0.32, \mathrm{P}=0.029$ ). (C) Expression of E7 transcripts in stably transfected Saos-2 cells. Black arrows indicate the E7 oncogene and $\beta 2 \mathrm{M}$ expression, respectively. miR-21 and miR-143 are normalized by U6 snRNA. Each point represents the mean of three independent experiments. Bars represent mean. Error bars represent SD. Statistical significance was determined as $\mathrm{P}<0.05$. $\beta 2 \mathrm{M}$, $\beta$-2-microglobulin.
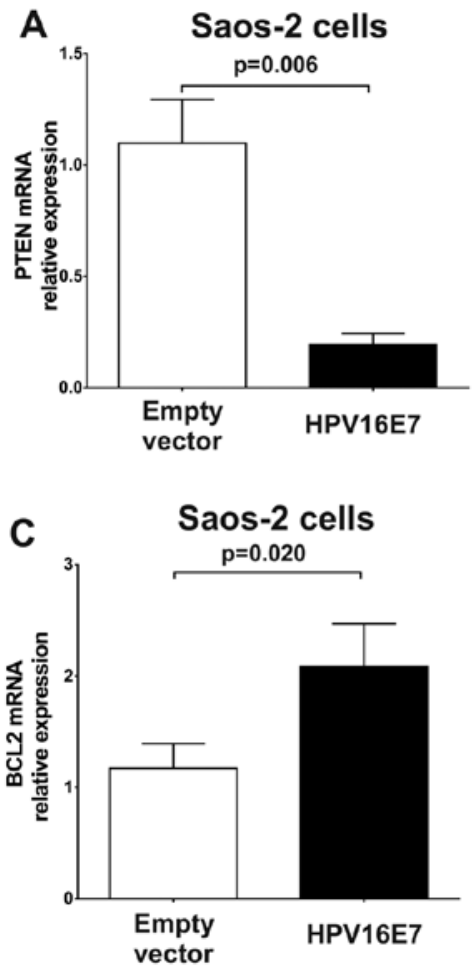
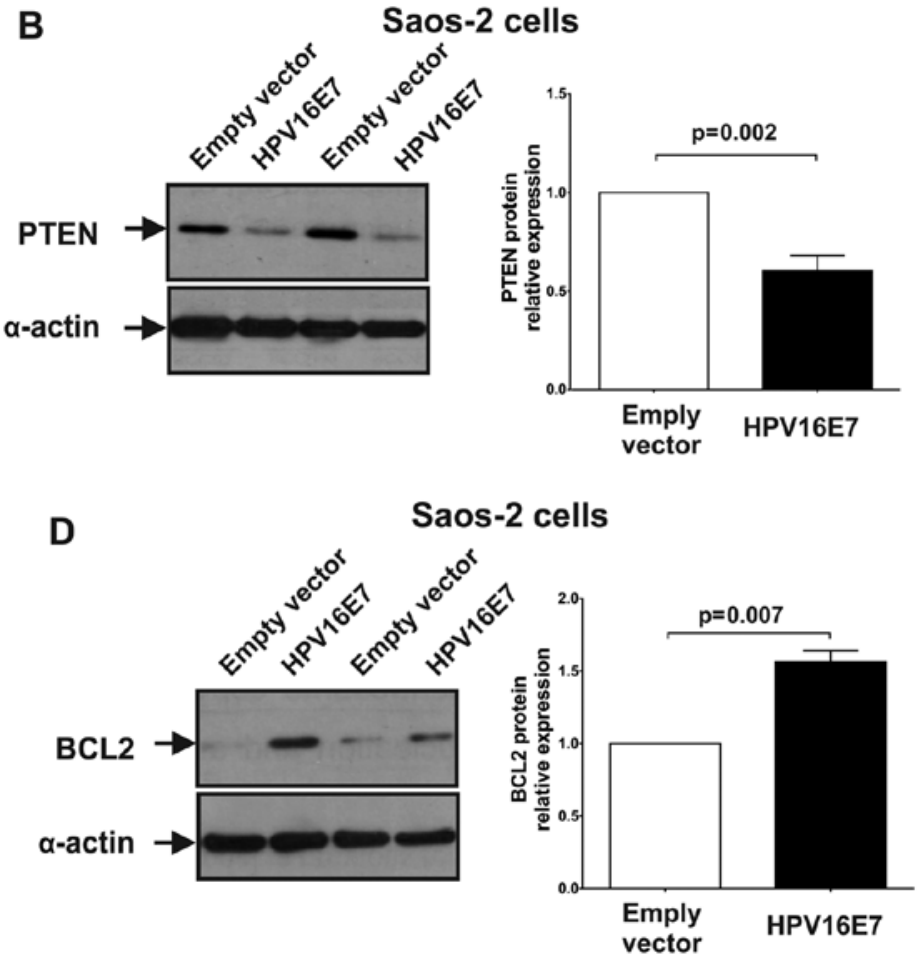

Figure 4. PTEN downregulation and BCL2 upregulation induced by the HPV16 E7 oncoprotein. Saos-2 cells were stably transfected, as indicated in Materials and methods. (A and C) RT-qPCR analysis was performed to determine PTEN and BCL2 mRNA expression levels, respectively, in stably transfected Saos-2 cells. (B and D) Western blot analysis (WB) and quantitative densitometry of PTEN and BCL2 proteins in stably transfected Saos-2 cells. Three independent RT-qPCR experiments were performed and values are expressed as means \pm SD (normalized to HPRT); Mann-Whitney test was performed and statistical significance was determined as $\mathrm{P}<0.05$, comparing expression in Saos- 2 cells transfected with pcDNA3 (empty vector) vs. Saos-2 cells transfected with plasmid expressing E7 (pcDNA3E7). WB experiments were performed in three independent cell cultures and normalized to $\alpha$-actin. A representative experiment is shown in panels B and D. Bars represent mean. Error bars represent SD. 
A

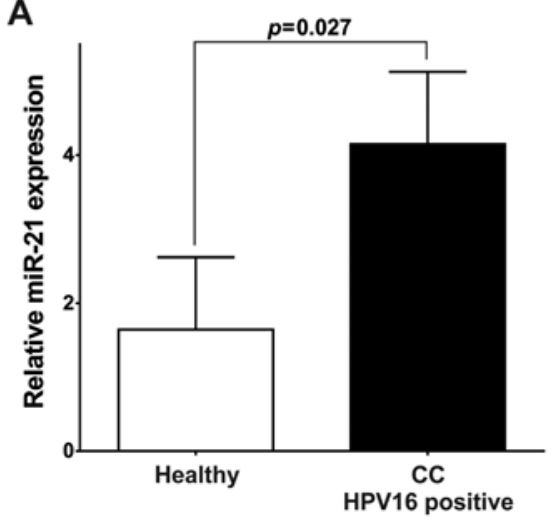

B

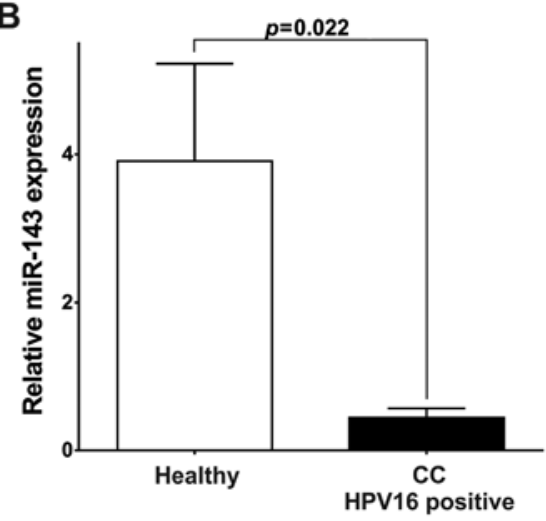

Figure 5. miR-21 and miR-143 expression in HPV16-positive cervical cancer patients and healthy individuals. Ten normal cervical scrapings negative for human papillomavirus (HPV) and 14 cervical cancer (CC) samples positive for HPV16 were used to detect the mature form of miRNAs, as indicated in Materials and methods. Data obtained by real-time RT-PCR amplification of miR-21 and miR-143 are plotted. (A) The expression level of miR-21 was significantly higher (median $\pm \mathrm{SD} ; 4.15 \pm 0.97, \mathrm{P}=0.027)$ in HPV16-positive CC patients as compared with the healthy individuals. (B) The expression level of miR-143 in HPV16-positive cervical cancer patients was significantly lower (median $\pm \mathrm{SD} ; 0.44 \pm 0.12, \mathrm{P}=0.022$ ) than in the healthy individuals. miR-21 and miR-143 are normalized by U6 snRNA. Bars represent the the mean. Error bars represent standard deviation (SD).

was significantly repressed in miR-21-upregulated Saos-2 cells compared to control (stably transfected pcDNA3 cells) [PTEN mRNA: $0.19(\mathrm{P}=0.006)$; PTEN protein: $0.60(\mathrm{P}=0.002)]$. The results indicated that miR-21 upregulation, which is caused by the HPV16 E7 oncoprotein, represses PTEN expression.

The E7 oncoprotein upregulates expression of BCL-2 by downregulating miR-143. We observed that in Saos-2 cells the E7 oncoprotein downregulated $(0.57$-fold, $\mathrm{P}=0.029)$ the expression of miR-143 (Fig. 3B). To explore whether the downregulation of miR-143 in Saos-2 cells expressing the E7 oncoprotein can increase the expression of its target genes, BCL-2, mRNA and protein levels for this gene were quantified. As shown in Fig. 4C and D, the expression of BCL-2 was significantly upregulated in E7 expressing Saos-2 cells [BCL-2 mRNA: $2.09(\mathrm{P}=0.020)$; BCL-2 protein: $1.56(\mathrm{P}=0.007)$ ]. These results suggest that $\mathrm{miR}-143$ downregulation by the HPV16 E7 oncoprotein leads to BCL-2 overexpression.

Expression of miR-21 and miR-143 is altered by HPV16 in cervical cancer. We confirmed the pattern of miR-21 and miR-143 expression in samples obtained from HPV16positive $\mathrm{CC}$ patients compared with cervical scrapings from HPV-negative healthy individuals, as previously reported in cell lines and HPV-positive samples $(23,24)$. TaqMan RT-qPCR assays showed that miR-21 levels were significantly higher (4.15, $\mathrm{P}=0.027$; Fig. 5A) and miR-143 significantly lower $(0.44$, $\mathrm{P}=0.021$; Fig. 5B) in the HPV16-positive $\mathrm{CC}$ patients than in HPV-negative healthy individuals. These results support the hypothesis that HPV16 through its oncogenic oncoproteins plays a role in the deregulation of miR-21 and miR-143 expression.

\section{Discussion}

HPV infection and 17 $\beta$-estradiol $\left(\mathrm{E}_{2}\right)$ are risk factors for $\mathrm{CC}$ development $(5,35,36)$; $~ 95 \%$ of these cancers are associated with persistent HR-HPV infection (36). HR-HPV have been reported to modify the expression patterns of certain
miRNAs (17-21), but the specific involvement of the HPV16 E7 oncoprotein and $E_{2}$ has not been explored. In the present study, using a mouse model for HPV-associated cervical carcinogenesis (K14E7 transgenic mice), we aimed to investigate whether the high miR-21 and low miR-143 expression levels in CC are associated with the HVP16 E7 oncoprotein and $E_{2}$. In addition, using a cell line that expressed HPV16 E7 oncoprotein we determined if the E7 oncoprotein was involved in the deregulation of miR-21 and miR-143 in vitro. Squamous epithelial neoplasia in these animals progresses from low-grade squamous intraepithelial lesion to high-grade cervical dysplasia and ultimately invasive cervical malignancies after six months exposure to a chronic low-dose of $\mathrm{E}_{2}$, mimicking malignant progression in women (5). It is widely known that miR-21 is the most highly overexpressed miRNA in numerous cancers including cervical cancer (17-21), and that in HPV-positive samples miR-21 expression correlates with the progression of high grade cervical lesions to CC making it a credible biomarker for HPV-associated cervical carcinogenesis (37). Here, we observed in the K14E7 murine model and cell lines expressing HPV16 E7 oncoprotein a strong upregulation of miR-21 compared to controls. We also found in transgenic and NT mice that $\mathrm{E}_{2}$ treatment induces an increase in miR-21 expression levels. This is similar to the situation observed in breast cancers where it was reported that $E_{2}$ induced expression of this important miRNA $(32,38)$. These results suggest that HPV16 E7 oncoprotein induces miR-21 expression both in vivo and in vitro and that $\mathrm{E}_{2}$ may cooperate in this effect.

Many different miR-21 target genes, such as TPM1, PDCD4, CCL20 and PTEN tumor suppressor have been reported $(25,39)$. For example, it was observed that miR-21 overexpression was associated with downregulation of the tumor-suppressive PTEN in endometrial cancer (40) and HPV-positive cervical cancers (41). Based on these results, we investigated if the presence of the HPV16 E7 oncoprotein alone or in conjunction with $\mathrm{E}_{2}$ induced a similar effect on the expression of a miR-21 target gene. In the present study, we performed matched analyses of miR-21 and PTEN mRNA 


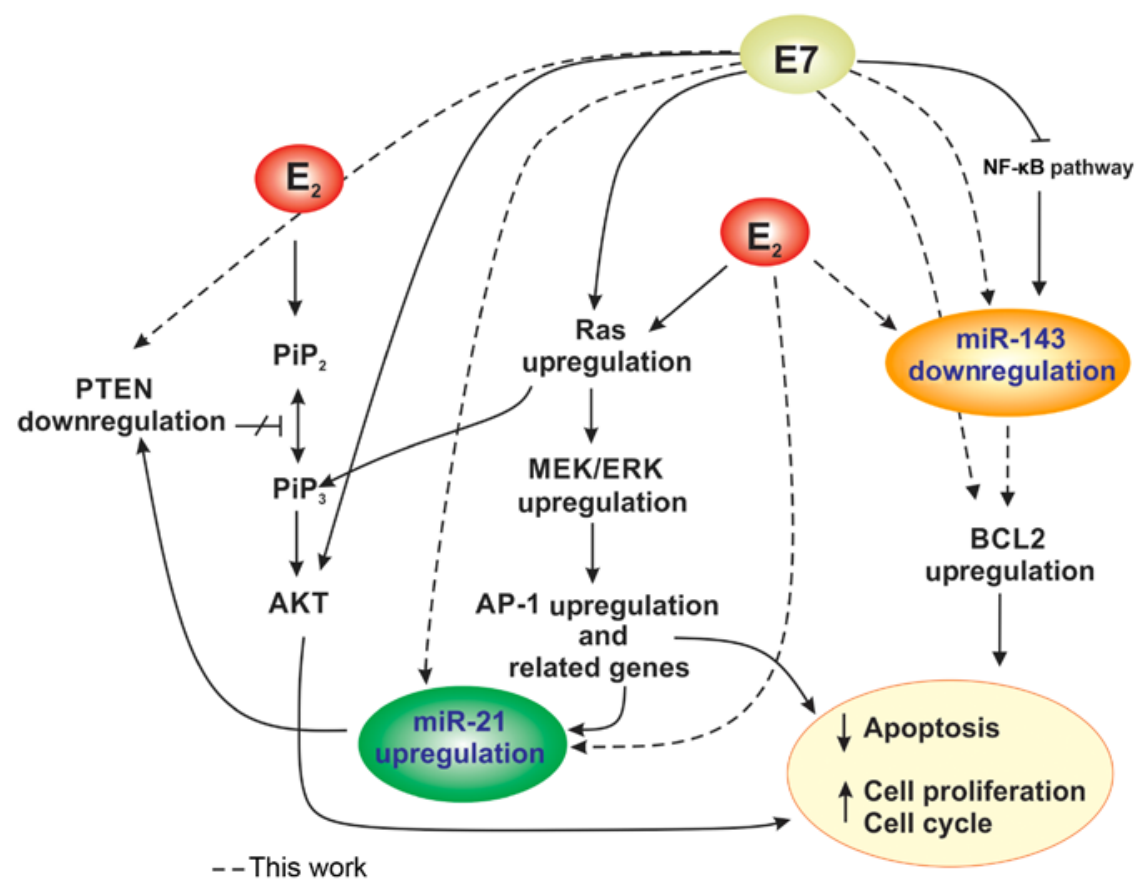

Figure 6. Model on how HPV16 E7 oncoprotein and $\mathrm{E}_{2}$ may alter miRNA levels and cellular processes. HPV16 E7 oncoprotein and estradiol upregulates miR-21 expression through activation Ras and MEK/ERK pathway, whose upregulation leads to AP-1 activation, which acts as a transcription factor for miR21. The miR-21 upregulation promotes cell growth and cell proliferation by inhibition of its target genes (such as PTEN), avoiding the regulation of PI3K/AKT pathway; this pathway is also favored by the upregulation of Ras through HPV16 E7 oncoprotein and estrogen. Additionally, the HPV16 E7 oncoprotein and estrogen downregulates the tumor suppressive. miR-143 leading to upregulation of BCL2 protein, allowing protection from apoptosis. Thus, HPV16 E7 and estradiol, though miRNA modulation, play an important role in CC increasing cell growth, proliferation and cell survival. See Discussion section for details and references.

and protein expression in cervical tissue obtained from the K14E7 mouse model in the presence or absence of $E_{2}$ as well as from the Saos-2 cell line expressing E7; we observed that PTEN mRNA and protein levels were downregulated in both the K14E7 model and the Saos-2 cell line expressing HPV16 E7. Likewise, our results showed a significantly negative correlation between miR-21 levels and PTEN protein and mRNA expression, suggesting that both in vivo and in vitro the HPV16 E7 oncoprotein dowregulates PTEN through the upregulation of miR-21. Notably, our results show that miR-21 was upregulated in NT mice treated with $\mathrm{E}_{2}$, but PTEN mRNA and protein levels were also remarkably increased in these mice, indicating that a chronic physiological dose of $17 \beta$-estradiol induces upregulation of PTEN in cervical tissue as previously reported in the HepG2 cell line and leiomyomas where the increase in PTEN expression was attributed to $E_{2}(42,43)$. As compared with $\mathrm{NT}+\mathrm{E}_{2}$ mice, $\mathrm{PTEN}$ was strongly repressed in both K14E7 and K14E7+ $\mathrm{E}_{2}$ mice (Fig. 2A and B), and the effect is attributed to the E7 oncoprotein.

The high expression of miR-21 in the K14E7 murine model could be explained by a similar signaling pathway induced by the E7 and $\mathrm{E}_{2}$ treatment. The Ras/ERK pathway plays an important role in tumorigenesis and it is well known that the E7 expression and $E_{2}$ cause activation of this pathway $(44,45)$. ERK signal activates AP-1 as well as c-Jun and c-Fos, which regulate expression of genes involved in cell proliferation, differentiation, malignant transformation and metastasis (46). In this sense, it has been reported that the E7 oncoprotein upregulates the expression of AP-1 (44) and $\mathrm{E}_{2}$ increases the signaling activity of this transcriptional factor (47). The activation of AP-1 could increase the miR-21 levels because it was reported that AP-1 activates miR-21 transcription through conserved AP-1 binding sites in its promoter (48), which would explain the increase in miR-21 expression found by both HPV16 E7 oncoprotein and $\mathrm{E}_{2}$ treatment.

The increased expression level of miR-21 induced by HPV16 E7 oncoprotein and $E_{2}$ might represent an important step towards the development of CC since the majority of its reported targets are tumor suppressors, such as PTEN, frequently found diminished in CC $(41,49)$. PTEN negatively regulates cell proliferation by blocking the PI3K/AKT signaling pathway (50), a pathway known to play a key role in numerous cellular functions including proliferation, adhesion, angiogenesis and migration (51). On the other hand, it has been reported that E7 oncoprotein and $17 \beta$-estradiol upregulate the AKT signaling pathway $(52,53)$. The ability of HPV 16 E7 oncoprotein to upregulate AKT activity depends on the inactivation of the retinoblastoma $(\mathrm{Rb})$ gene product family of proteins (52), while $\mathrm{E}_{2}$ can activate the PI3K/AKT pathway by an ER-dependent action (53). Thus, PI3K/AKT activation is achieved by several mechanisms, including the upregulation of miR-21 and inactivation of PTEN in presence of the E7 oncoprotein and $\mathrm{E}_{2}$ (Fig. 6).

miR-143 acts as a tumor suppressor and it has been reported downregulated in HPV-positive cell lines and CC $(17-21,23,24,27,54)$. In the present study, we found that miR-143 expression is downregulated in the K14E7 model and cell lines expressing HPV16 E7; we also observed that miR-143 expression levels were significantly downregulated by $E_{2}$ in transgenic and NT mice treated with $E_{2}$, as reported in 
breast cancer (32). Our results suggest for the first time that the E7 oncoprotein may downregulate miR-143 expression both in vivo and in vitro and that $\mathrm{E}_{2}$ treatment is also implicated in the downregulation of this important miRNA in vivo.

miR-143 is involved in the negative regulation of BCL-2 expression in CC (27), and the suppressive effects of miR-143 on cell proliferation and promotion of apoptosis is, at least in part, through suppression of BCL-2 expression (27). Moreover, it has been reported that the abnormal activation of Bcl-2 is in agreement with a significant increase in the resistance to apoptosis in E7-transfected cells (55). In the same manner, $\mathrm{E}_{2}$ inhibits apoptosis partially by the induction of BCL-2 transcription (56). Here, we observed that both mRNA and protein levels of BCL-2 were remarkably enhanced in the K14E7 mice model and cell lines expressing the HPV16 E7 oncoprotein. Likewise, BCL-2 expression was increased in mice treated with $\mathrm{E}_{2}$, indicating that estrogen induces upregulation of BCL-2 in mouse cervical tissue, similarly to the effect observed in MCF-7 cells (56). Otherwise, we determined an inverse relationship between miR-143 expression and BCL-2 mRNA and protein levels, comparable to that found in cervical cell lines and human cervical tumors (27). A possible explanation for the low expression of miR-143 in our murine model is that this miRNA is transcribed by nuclear factor kappa $\mathrm{B}(\mathrm{NF}-\kappa \mathrm{B})(57)$, which is attenuated by the $\mathrm{E} 7$ oncoprotein (58); therefore, in the presence of E7 the downregulation of miR-143 could result in overexpression of BCL-2, thereby blocking apoptosis (Fig. 6).

We also confirmed in CC samples containing HPV16 that miR-21 expression was significantly increased, while miR-143 expression was decreased with respect to cervical scrapings (HPV-negative), as reported in HPV-infected CC (17-21). This is consistent with the hypothesis that the HPV16 E7 oncoprotein is responsible for the deregulation of these miRNAs in HPV16-positive CC patients.

In conclusion, we demonstrated a role for the HPV16 E7 oncoprotein and $E_{2}$ in the regulation of miR-21 and miR-143 expression in cervical tissue. Two major trends were shown in the presence of the HPV16 E7 oncoprotein in vivo and in vitro: i) miR-21 overexpression and downregulation of PTEN and ii) miR-143 expression was reduced, while BCL-2 was overexpressed. We also showed that $\mathrm{E}_{2}$ is involved in deregulating the expression levels of miR-21 and miR-143 in vivo. We posit that these alterations in host gene regulation contribute to changes in several biological processes including cell proliferation and apoptosis that lead to $\mathrm{CC}$. These findings not only provide insight into the interplay between the HPV16 E7 oncoprotein, $\mathrm{E}_{2}$ and miRNAs in cervical tissue, but also opens up new diagnostic perspectives in $\mathrm{CC}$.

\section{Acknowledgments}

The present study was supported by the National Council of Science and Technology of México (CONACYT), Grants 0253804 (AGC) and 00201904 (PG). Yazmín Gómez-Gómez was a recipient of doctoral fellowships from CONACYT (46244). The study is part of the doctoral dissertation project of Yazmín Gómez-Gómez, a student of the Posgrado en Ciencias Biomédicas, Instituto de Fisiología Celular, Universidad Nacional Autónoma de México (UNAM). The authors would like to thank Gabriela Mora, Lauro Macías, Elizabeth Alvarez Rios (CINVESTAV-IPN) and Dra. Marcela Lizano-Soberón (Unidad de Investigación Biomédica en Cáncer, Instituto Nacional de Cancerología) for technical support.

\section{References}

1. Jemal A, Bray F, Center MM, Ferlay J, Ward E and Forman D: Global cancer statistics. CA Cancer J Clin 61: 69-90, 2011.

2. zur Hausen H: Papillomaviruses and cancer: From basic studies to clinical application. Nat Rev Cancer 2: 342-350, 2002.

3. Crosbie EJ, Einstein MH, Franceschi S and Kitchener HC: Human papillomavirus and cervical cancer. Lancet 382: 889-899, 2013.

4. Münger K, Baldwin A, Edwards KM, Hayakawa H, Nguyen CL, Owens M, Grace M and Huh K: Mechanisms of human papillomavirus-induced oncogenesis. J Virol 78: 11451-11460, 2004.

5. Riley RR, Duensing S, Brake T, Münger K, Lambert PF and Arbeit JM: Dissection of human papillomavirus E6 and E7 function in transgenic mouse models of cervical carcinogenesis. Cancer Res 63: 4862-4871, 2003.

6. McLaughlin-Drubin ME and Münger K: The human papillomavirus E7 oncoprotein. Virology 384: 335-344, 2009.

7. Ghittoni R, Accardi R, Hasan U, Gheit T, Sylla B and Tommasino M: The biological properties of E6 and E7 oncoproteins from human papillomaviruses. Virus Genes 40: 1-13, 2010.

8. Nilsson S, MäkeläS, TreuterE, Tujague M, Thomsen J, Andersson G, Enmark E, Pettersson K, Warner M and Gustafsson JA: Mechanisms of estrogen action. Physiol Rev 81: 1535-1565, 2001.

9. Gruber CJ, Tschugguel W, Schneeberger C and Huber JC: Production and actions of estrogens. N Engl J Med 346: 340-352, 2002.

10. Bartel DP: MicroRNAs: Genomics, biogenesis, mechanism, and function. Cell 116: 281-297, 2004.

11. Zhang B, Pan X, Cobb GP and Anderson TA: microRNAs as oncogenes and tumor suppressors. Dev Biol 302: 1-12, 2007.

12. Hayashita Y, Osada H, Tatematsu Y, Yamada H, Yanagisawa K, Tomida S, Yatabe Y, Kawahara K, Sekido Y and Takahashi T: A polycistronic microRNA cluster, miR-17-92, is overexpressed in human lung cancers and enhances cell proliferation. Cancer Res 65: 9628-9632, 2005.

13. Jovanovic $M$ and Hengartner MO: miRNAs and apoptosis: RNAs to die for. Oncogene 25: 6176-6187, 2006.

14. Calin GA, Sevignani C, Dumitru CD, Hyslop T, Noch E, Yendamuri S, Shimizu M, Rattan S, Bullrich F, Negrini M, et al: Human microRNA genes are frequently located at fragile sites and genomic regions involved in cancers. Proc Natl Acad Sci USA 101: 2999-3004, 2004.

15. Lu J, Getz G, Miska EA, Alvarez-Saavedra E, Lamb J, Peck D, Sweet-Cordero A, Ebert BL, Mak RH, Ferrando AA, et al: MicroRNA expression profiles classify human cancers. Nature 435: 834-838, 2005.

16. Calin GA, Dumitru CD, Shimizu M, Bichi R, Zupo S, Noch E, Aldler H, Rattan S, Keating M, Rai K, et al: Frequent deletions and down-regulation of micro-RNA genes miR15 and miR16 at $13 q 14$ in chronic lymphocytic leukemia. Proc Natl Acad Sci USA 99: 15524-15529, 2002.

17. McBee WC, Gardiner AS, Edwards RP, Lesnock JL and Bhargava R: MicroRNA analysis in human papillomavirus (HPV)-associated cervical neoplasia and cancer. J Carcinog Mutagen 1: 1-9, 2011.

18. Pereira PM, Marques JP, Soares AR, Carreto L and Santos MAS: MicroRNA expression variability in human cervical tissues. PLoS One 5: el1780, 2010.

19. Li Y, Wang F, Xu J, Ye F, Shen Y, Zhou J, Lu W, Wan X, Ma D and Xie X: Progressive miRNA expression profiles in cervical carcinogenesis and identification of HPV-related target genes for miR-29. J Pathol 224: 484-495, 2011.

20. Lui WO, Pourmand N, Patterson BK and Fire A: Patterns of known and novel small RNAs in human cervical cancer. Cancer Res 67: 6031-6043, 2007.

21. Wang X, Tang S, Le SY, Lu R, Rader JS, Meyers C and Zheng ZM: Aberrant expression of oncogenic and tumor-suppressive microRNAs in cervical cancer is required for cancer cell growth. PLoS One 3: e2557, 2008.

22. Gómez-Gómez Y, Organista-Nava J and Gariglio P: Deregulation of the miRNAs expression in cervical cancer: Human papillomavirus implications. Biomed Res Int 2013: 407052, 2013. doi: $10.1155 / 2013 / 407052$. 
23. Deftereos G, Corrie SR, Feng Q, Morihara J, Stern J, Hawes SE and Kiviat NB: Expression of mir-21 and mir-143 in cervical specimens ranging from histologically normal through to invasive cervical cancer. PLoS One 6: e28423, 2011

24. Liu L, Wang YL and Wang JF: Differential expression of miR-21, miR-126, miR-143, miR-373 in normal cervical tissue, cervical cancer tissue and HeLa cell. Sichuan Da Xue Xue Bao Yi Xue Ban 43: 536-539, 2011 (In Chinese).

25. Yao Q, Xu H, Zhang QQ, Zhou H and Qu LH: MicroRNA-21 promotes cell proliferation and down-regulates the expression of programmed cell death 4 (PDCD4) in HeLa cervical carcinoma cells. Biochem Biophys Res Commun 388: 539-542, 2009.

26. Iliopoulos D, Jaeger SA, Hirsch HA, Bulyk ML and Struhl K: STAT3 activation of miR-21 and miR-181b-1 via PTEN and CYLD are part of the epigenetic switch linking inflammation to cancer. Mol Cell 39: 493-506, 2010.

27. Liu L, Yu X, Guo X, Tian Z, Su M, Long Y, Huang C, Zhou F, Liu M, Wu X, et al: miR-143 is downregulated in cervical cancer and promotes apoptosis and inhibits tumor formation by targeting Bcl-2. Mol Med Rep 5: 753-760, 2012.

28. Pillai MR, Halabi S, McKalip A, Jayaprakash PG, Rajalekshmi TN, Nair MK and Herman B: The presence of human papillomavirus-16/-18 E6, $\mathrm{p} 53$, and $\mathrm{Bcl}-2$ protein in cervicovaginal smears from patients with invasive cervical cancer. Cancer Epidemiol Biomarkers Prev 5: 329-335, 1996.

29. Dimitrakakis C, Kymionis G, Diakomanolis E, Papaspyrou I, Rodolakis A, Arzimanoglou I, Leandros E and Michalas S: The possible role of p53 and bcl-2 expression in cervical carcinomas and their premalignant lesions. Gynecol Oncol 77: 129-136, 2000.

30. Myklebust MP, Bruland O, Fluge $\varnothing$, Skarstein A, Balteskard L and Dahl O: MicroRNA-15b is induced with E2F-controlled genes in HPV-related cancer. Br J Cancer 105: 1719-1725, 2011.

31. Zhang S, Liu F, Mao X, Huang J, Yang J, Yin X, Wu L, Zheng L and Wang Q: Elevation of miR-27b by HPV16 E7 inhibits PPAR $\gamma$ expression and promotes proliferation and invasion in cervical carcinoma cells. Int J Oncol 47: 1759-1766, 2015.

32. Bhat-Nakshatri P, Wang G, Collins NR, Thomson MJ, Geistlinger TR, Carroll JS, Brown M, Hammond S, Srour EF, Liu Y, et al: Estradiol-regulated microRNAs control estradiol response in breast cancer cells. Nucleic Acids Res 37: 4850-4861, 2009.

33. Herber R, Liem A, Pitot H and Lambert PF: Squamous epithelial hyperplasia and carcinoma in mice transgenic for the human papillomavirus type 16 E7 oncogene. J Virol 70: 1873-1881, 1996.

34. Nolan T, Hands RE and Bustin SA: Quantification of mRNA using real-time RT-PCR. Nat Protoc 1: 1559-1582, 2006.

35. Arbeit JM, Howley PM and Hanahan D: Chronic estrogeninduced cervical and vaginal squamous carcinogenesis in human papillomavirus type 16 transgenic mice. Proc Natl Acad Sci USA 93: 2930-2935, 1996.

36. International Collaboration of Epidemiological Studies of Cervical Cancer: Comparison of risk factors for invasive squamous cell carcinoma and adenocarcinoma of the cervix: Collaborative reanalysis of individual data on 8,097 women with squamous cell carcinoma and 1,374 women with adenocarcinoma from 12 epidemiological studies. Int J Cancer 120: 885-891, 2007.

37. Gocze K, Gombos K, Kovacs K, Juhasz K, Gocze P and Kiss I: MicroRNA expressions in HPV-induced cervical dysplasia and cancer. Anticancer Res 35: 523-530, 2015.

38. Mattie MD, Benz CC, Bowers J, Sensinger K, Wong L, Scott GK, Fedele V, Ginzinger D, Getts R and Haqq C: Optimized highthroughput microRNA expression profiling provides novel biomarker assessment of clinical prostate and breast cancer biopsies. Mol Cancer 5: 24, 2006.

39. Yao T and Lin Z: MiR-21 is involved in cervical squamous cell tumorigenesis and regulates CCL20. Biochim Biophys Acta 1822: 248-260, 2012 .
40. Qin X, Yan L, Zhao X, Li C and Fu Y: microRNA-21 overexpression contributes to cell proliferation by targeting PTEN in endometrioid endometrial cancer. Oncol Lett 4: 1290-1296, 2012.

41. Xu J, Zhang W, Lv Q and Zhu D: Overexpression of miR-21 promotes the proliferation and migration of cervical cancer cells via the inhibition of PTEN. Oncol Rep 33: 3108-3116, 2015.

42. Jeong YJ, Noh EM, Lee YR, Yu HN, Jang KY, Lee SJ, Kim J and Kim JS: 17beta-estradiol induces up-regulation of PTEN and PPARgamma in leiomyoma cells, but not in normal cells. Int J Oncol 36: 921-927, 2010.

43. Marino M, Acconcia F and Trentalance A: Biphasic estradiolinduced AKT phosphorylation is modulated by PTEN via MAP kinase in HepG2 cells. Mol Biol Cell 14: 2583-2591, 2003.

44. Yuan H, Ito S, Senga T, Hyodo T, Kiyono T, Kikkawa F and Hamaguchi M: Human papillomavirus type 16 oncoprotein E7 suppresses cadherin-mediated cell adhesion via ERK and AP-1 signaling. Int J Oncol 35: 309-314, 2009.

45. Miñano A, Xifró X, Pérez V, Barneda-Zahonero B, Saura CA and Rodríguez-Alvarez J: Estradiol facilitates neurite maintenance by a Src/Ras/ERK signalling pathway. Mol Cell Neurosci 39: $143-151,2008$.

46. Eferl R and Wagner EF: AP-1: A double-edged sword in tumorigenesis. Nat Rev Cancer 3: 859-868, 2003.

47. Kakehashi A, Tago Y, Yoshida M, Sokuza Y, Wei M, Fukushima S and Wanibuchi H: Hormonally active doses of isoflavone aglycones promote mammary and endometrial carcinogenesis and alter the molecular tumor environment in Donryu rats. Toxicol Sci 126: 39-51, 2012.

48. Fujita S, Ito T, Mizutani T, Minoguchi S, Yamamichi N, Sakurai K and Iba H: miR-21 Gene expression triggered by AP-1 is sustained through a double-negative feedback mechanism. J Mol Biol 378: 492-504, 2008.

49. Vázquez-Ulloa E, Lizano M, Avilés-Salas A, Alfaro-Moreno E and Contreras-Paredes A: Abnormal distribution of hDlg and PTEN in premalignant lesions and invasive cervical cancer. Gynecol Oncol 122: 663-668, 2011.

50. Leslie NR and Downes CP: PTEN: The down side of PI 3-kinase signalling. Cell Signal 14: 285-295, 2002.

51. Bader AG, Kang S, Zhao L and Vogt PK: Oncogenic PI3K deregulates transcription and translation. Nat Rev Cancer 5: 921-929, 2005.

52. Menges CW, Baglia LA, Lapoint R and McCance DJ: Human papillomavirus type 16 E7 up-regulates AKT activity through the retinoblastoma protein. Cancer Res 66: 5555-5559, 2006.

53. Guo RX, Wei LH, Tu Z, Sun PM, Wang JL, Zhao D, Li XP and Tang JM: $17 \beta$-estradiol activates PI3K/Akt signaling pathway by estrogen receptor (ER)-dependent and ER-independent mechanisms in endometrial cancer cells. J Steroid Biochem Mol Biol 99: 9-18, 2006

54. Martinez I, Gardiner AS, Board KF, Monzon FA, Edwards RP and Khan SA: Human papillomavirus type 16 reduces the expression of microRNA-218 in cervical carcinoma cells. Oncogene 27: 2575-2582, 2008

55. Du J, Chen GG, Vlantis AC, Chan PKS, Tsang RKY and van Hasselt CA: Resistance to apoptosis of HPV 16-infected laryngeal cancer cells is associated with decreased Bak and increased Bcl-2 expression. Cancer Lett 205: 81-88, 2004.

56. Perillo B, Sasso A, Abbondanza C and Palumbo G: $17 \beta$-estradiol inhibits apoptosis in MCF-7 cells, inducing bcl-2 expression via two estrogen-responsive elements present in the coding sequence. Mol Cell Biol 20: 2890-2901, 2000.

57. Zhang X, Liu S, Hu T, Liu S, He Y and Sun S: Up-regulated microRNA-143 transcribed by nuclear factor kappa B enhances hepatocarcinoma metastasis by repressing fibronectin expression. Hepatology 50: 490-499, 2009.

58. Spitkovsky D, Hehner SP, Hofmann TG, Möller A and Schmitz ML: The human papillomavirus oncoprotein E7 attenuates NF- $\kappa \mathrm{B}$ activation by targeting the Ikappa B kinase complex. J Biol Chem 277: 25576-25582, 2002. 